\title{
HOMENAGEM AO PROFESSOR WASHINGTON PELUSO ALBINO DE SOUSA: ESTUDOS SOBRE WPAS
}

TRIBUTE TO PROFESSOR WASHINGTON PELUSO ALBINO DE SOUSA: STUDIES ON WPAS

Eros Roberto Grau*

Não pretendo fazer o necrológio do Professor Washington Peluso Albino, porém lembrar aos mais jovens o grande jurista que se foi. No dia seguinte à sua morte, há oito dias, ${ }^{1}$ escrevi um pequeno texto reproduzido pelo site do Consultor Jurídico.

Washington Peluso Albino de Souza ingressou na Faculdade de Direito da UFMG em 1933 e, assim que se formou, começou, lá mesmo, a ensinar Economia Política. Na UFMG obteve os títulos de Doutor, Livre-Docente e Professor Titular. Viveu intensamente em torno da Faculdade; coordenou seus cursos de pós-graduação, foi seu Diretor. A ele se deve a introdução na sua grade curricular da disciplina Direito Econômico. Criou em agosto de 1972 a Fundação Brasileira de Direito Econômico, que subsiste mercê do entusiasmo e dedicação de Giovani Clark.

Publicou inúmeros livros, primeiro deles a tese Ensaio de conceituação jurídica do preço, ${ }^{2}$ na qual a ideia de Direito Econômico é esboçada. Dois anos após, o Apontamentos de Economia Política aplicada ao Direito, ${ }^{3}$ que a afirma. De todos, destaco o Do econômico nas Constituições vigentes, editado pela Revista Brasileira de Estudos Políticos, ${ }^{4}$ em dois volumes, no qual afirma "o Direito Econômico como disciplina do estudo jurídico" e trabalha o conceito de economicidade, fundamental na construção de sua obra. ${ }^{5}$

Washington foi o pai do Direito Econômico brasileiro. Em um texto antigo, ${ }^{6}$ em que procurei indicar alguns traços da sua história entre nós, menciono um artigo de 1957, de Washington - Direito Econômico; do "Econômico" como conteúdo do Direito" -,

* Professor Titular aposentado do Departamento de Direito Econômico-Financeiro da Faculdade de Direito da Universidade de São Paulo. Ex-Ministro do Supremo Tribunal Federal

Escrevo esta nota no dia 24 de junho de 2011.

Edição da Imprensa Oficial, Belo Horizonte, em 1949.

Dois volumes editados pelo Centro de Estudos Econômicos de Minas Gerais, Belo Horizonte, 1951 e 1954. Belo Horizonte, 1961.

Em seguida vieram outros artigos e livros, entre os quais menciono, em suas primeiras edições: Direito Econômico e Economia Política. Belo Horizonte: Editora Prisma, 1970 (v. 1) e 1971 (v. 2); Primeiras Linhas do Direito Econômico. Belo Horizonte: Editora Fundação Brasileira de Direito Econômico, 1977; Direito Econômico. São Paulo: Editora Saraiva, 1980; Teoria da Constituição Econômica. Belo Horizonte: Del Rey, 2002.

6 -Planejamento econômico e regra jurídica. São Paulo: Revista dos Tribunais, 1978. p. 209-214.

7 In: Jurisprudência Mineira, 1957, v. 1, p. 213-225; v. 2, p. 153-166. 
que consubstanciaria a sua certidão de nascimento. Hoje estou certo, contudo, de que essa certidão foi lavrada na tese de 1949.

Em 1995, iniciativa de seu dileto aluno Ricardo Antonio Lucas Camargo, hoje professor na UFRGS - publicou-se, em sua homenagem, Desenvolvimento Econômico e intervenção do Estado na ordem constitucional, ${ }^{8}$ que José Paulo Sepúlveda Pertence, também aluno de Washington, prefaciou. Em Ricardo e em Giovani deposito a esperança da preservação da sua memória.

$* * *$

Washington defendeu, sob o entusiasmo que caracterizava a afirmação de suas convicções, a criação da Petrobrás. Liderou, em Minas, a campanha do O Petróleo é nosso. Coordenou o Plano de desenvolvimento do Estado de Minas Gerais na segunda metade dos anos cinquenta. Ameaçado após o golpe de 1964, encontrou exílio na França, onde viveu algum tempo.

Vai-se não apenas como grande jurista, mas também como mestre do barroco mineiro. Nos dois ensaios que compõem um belo livro publicado em $1978^{9}$ ensina as lições das vilas e cidades de Minas Gerais [“a cidade mineira tem caráter”, dizia] e sobre Adam Smith e o ouro de Minas.

Ensinou-me muito de Direito Econômico e, a mim e a Tania, sobre o barroco mineiro.

$* * *$

Aprendi, com o passar do tempo, a fazer tudo com mais pressa, serenamente. Por isso não resisto à tentação de relatar alguns episódios da nossa convivência.

Em 1972 o Professor Antonio Inácio Angarita da Silva convidou-me a dar aulas na disciplina de Direito Econômico, que criava na Fundação Getúlio Vargas, em São Paulo. Angarita havia sido aluno de Washington na UFMG.

Em maio de 1974 fui a Belo Horizonte fazer uma conferência sobre regiões metropolitanas, a convite do Professor Orlando de Carvalho, a quem disse, ao chegar, que tinha imensa vontade de conhecer o Professor Washington. O hotel era em frente à Faculdade. Pois se deu que em poucos minutos Washington veio ao meu encontro. Simples, generoso, desde o primeiro momento amigo. Pela sua mão conhecemos Minas, minha mulher e eu. Nossa existência em Tiradentes é devida a ele.

Três anos depois, maio de 1977, aconteceu no Caraça o I Seminário de Professores de Direito Econômico, invenção de Washington. Lá assinamos, no dia 21, a Carta do Caraça, ${ }^{10}$ um momento marcante para o Direito Econômico, embora caído

Sergio Antonio Fabris editor, Porto Alegre.

9 Ensaios sobre o Ciclo do Ouro, Imprensa Universitária da UFMG, Belo Horizonte, 1978, posteriormente ampliado e, acrescido de ilustrações, publicado sob o título Minas do Ouro e do Barroco - As Raízes Históricas da Cultura Mineira, Barlavento, Belo Horizonte, 2000.

10 A Carta do Caraça foi assinada por Afonso Insuela Pereira, Alberto Venancio Filho, Ana Maria Ferraz 
no esquecimento. Alguns meses, tempo depois ensaiamos, sempre por iniciativa do Washington, a criação de uma Associação Latino-Americana de Direito Econômico, cuja sede seria Tiradentes. Não deu certo, mas valeu a pena por conta das reuniões e conversas que o projeto nos proporcionou.

Não recordo a data precisa, mas terá sido no final dos anos setenta. Levamos Tania a conhecer o Colégio do Caraça, então ainda não recuperado, quase em ruínas após o incêndio de maio de 1968. Fomos os três à serra do Caraça. Washington era amigo dos padres; passamos dois dias caminhando sobre os passos do Irmão Lourenço de Nossa Senhora, o Távora fugido do Marques de Pombal. As acomodações eram simplesmente precárias. Havia fios elétricos tocando- se, perigosamente, no teto do quarto em que Tania e eu fomos hospedados. A comida, inesquecível: "salada de mato", "sopa de mato" --como explicava um deles --- um pão intragável e um conhaque imbebível, produzido pelos padres. No caminho visitamos, em Santa Bárbara, a Matriz de Santo Antonio, com o teto pintado pelo Mestre Ataíde.

Tempo bom.

Encontramo-nos inúmeras vezes, apenas por nos vermos, em seminários, em bancas de concursos. Em Minas, São Paulo, no Rio, em Brasília. Entre 1993 e 1994 em Brasília, quando fizemos parte da Comissão Especial de Revisão Constitucional, criada pelo Presidente da República, com a finalidade de identificar propostas de interesse fundamental no processo de revisão constitucional previsto no art. $3^{\circ}$ do Ato das Disposições Constitucionais Transitórias.

Horas e horas de conversas. Tempo bom.

$* * *$

No dia seguinte à morte de Washington, há oito dias, escrevi o pequeno texto $^{11}$ que transcrevo a seguir, ao encerrar esta nota.

Contemplo a linha do horizonte de repente reta, discreta. Como se estivesse em mar alto. Não existe mais, no horizonte, a serra de São José. Seu modo ser, barroco, diluiu-se. Já não se vê o horizonte que Washington ensinou-nos ao nos trazer, há quarenta anos, a Tiradentes. Sua ausência transtorna o horizonte.

Ensinou-me o Direito Econômico, que um professor da Faculdade de Direito da UFMG dizia ser "o Direito do Washington". Mais importante para a nossa existência, ensinou-nos a fraternidade mineira. Amigos como o professor Orlando de Carvalho e dona Lourdes. Ronaldo Cunha Campos, Ariosvaldo.

Augusto, Antonio Angarita da Silva, Eros Roberto Grau, Esteban Cotttely, Fábio Nusdeo, Geraldo Vidigal, José Alfredo de Oliveira Baracho, Mauricio Lourenço da Costa, Modesto Carvalhosa e Washington Peluso Albino de Souza.

11 Substituo aqui "a serra parecia ter mudado ou não haver mais" por "a serra mudou, parecia não haver mais" e "carinho" por "afeto". 
Apresentou-nos a Minas. O "chinesismo", dizia, de Sabará. Congonhas. O velho Caraça. Vinha a Tiradentes com o neto, Ricardo, e um cachorro amarrado em uma corda. Um dia corremos todo São João Del Rei à procura de bolinhos de feijão. As viagens com ele eram sempre longas, todos os arredores dos caminhos de Minas visitados, cada pequena estória e cada desvio da História palmilhados. Sua casa, na serra de BH, um mundo que Washington inventou, no qual não alcançávamos os livros, os livros nos alcançavam.

Foi-se o nosso Amigo. Contemplo a linha do horizonte de repente reta, vazia na sua ausência, um momento depois, contudo, recomposta. À imagem e semelhança da que os emboabas e os inconfidentes divisavam, tal como ele nos ensinou. Desde o momento da sua partida, no entanto, a serra mudou, parecia não haver mais, qual na Poesia. Foi-se o Amigo que nos deu Tiradentes e Minas de presente. Há de ter sido recebido com sorrisos de afeto pelos anjos, os anjos barrocos do Washington. 